\title{
Experiences of returning to elite beach volleyball after shoulder injury
}

\author{
Sofie Bele ${ }^{1}$, Anna Hafsteinsson Östenberg ${ }^{1, *}$, Rita Sjöström ${ }^{2,3}$, Marie Alricsson ${ }^{1,3}$ \\ 'Department of Sports Science, Linnaeus University, Kalmar/Växjö, Sweden \\ ${ }^{2}$ Region Jämtland Härjedalen, Unit of Research Education \& Development, Östersund, Sweden \\ ${ }^{3}$ Swedish Winter Sport Research Centre, Department of Health Sciences, Mid Sweden University, Östersund, Sweden
}

The purpose of this study was to examine beach volleyball players' experience regarding shoulder injury and how it affects their return to play. To achieve the research aims a qualitative design with semi-structured interviews had been conducted, five elite beach volleyball players, four men and one woman aged 27-42 participated in the study. All participants had suffered a severe shoulder injury, with absence from training and competing for at least 28 days. The findings of this study indicate that it is the individual's inner motivation, together with a clear goal and support from the community, family, teammate and coach that are the most important factors when going through rehabilitation and getting back to playing beach volleyball after a shoulder injury. All par- ticipants had been affected by their injury in some way; some of the participants had been affected in a positive way since they had become mentally stronger and had developed better volleyball technique after rehabilitation. The conclusions of this study indicate that there are three distinct factors that increase the chances of getting back to playing beach volleyball after shoulder injury; it is the players' self motivation, together with a clear goal and support from the community.

Keywords: Beach volleyball players, Qualitative method, Return to elite level, Sport injury, Rehabilitation

\section{INTRODUCTION}

Volleyball is one of the world's most popular team sports with about 150 million players in over 200 countries (Bahr and Bahr, 1997). When it comes to injuries in volleyball, Bahr and Reeser (2003) studied the frequency of incidents among the world's elite, during the Federation Internationale de Volley-Ball (FIVB) World Tour. They found a frequency of 3.1 injuries per player per 1,000 match hours. The incidents related to mainly knee-, ankle- and finger injuries, but overload injuries like low back pain and shoulder problems were also documented. The injury rate was significantly higher during games than actual practice. This is a similar occurrence as in soccer, where the injury rate increases during a match, compared to practice (Ekstrand et al., 2011). Shoulder injuries in volleyball seem predominantly to consist of impingement injuries and functional instability (Reeser et al., 2006).
Many athletes do not return to their respective sports after an injury (Johnson, 1997; Podlog and Eklund, 2005). Return to sport is affected by many factors, for example, psychological factors (Bandura, 2004). One of the psychological factors that may play a role in the comeback after injury is self-efficacy. The term is often used when people talk about rehabilitation and return after injury. High self-efficacy has been shown to have an effect on length of time prior to return after rehabilitation (Bandura, 1977). Johnson (1997) and Bandura (2004) suggest that high self-efficacy contributes to a faster come back after injury, including reaching the previous level of sports. It has also been found that competitive athletes are more prone to having a faster come back to sports than recreational athletes (Shaffer, 1991; Wiese-Björnsdal et al., 1998).

It has also been shown that high internal motivation to return to elite sport after injury brings a renewed positive attitude towards
${ }^{*}$ Corresponding author: Anna Hafsteinsson Östenberg

Department of Sports Science, Linnaeus University, SE-351 95 Växjö, Sweden

Tel: +46-734-216-246, Fax: +46-470-708-000,

E-mail: anna.hafsteinsson-ostenberg@lnu.se

Received: June 5, 2015 / Accepted: August 15, 2015
This is an Open Access article distributed under the terms of the Creative Commons Attribution Non-Commercial License (http://creativecommons.org/licenses/by-nc/3.0/) which permits unrestricted non-commercial use, distribution, and reproduction in any medium, provided the original work is properly cited. 
sports and athletics, although external motivation to return to the sport after injury tended to cause worry and concern for the task (Podlog and Eklund, 2005). Smith and Milliner, who investigated the emotional impact of sports injuries, highlight that health professionals and coaches need to pay attention to the, sometimes subtle, signs of depression that may occur in athletes after injury and during the rehabilitation process (Smith and Milliner, 1994).

An Integrated Model of Response to sports injury was presented by Wiese-Björnsdal et al. (1998). This model builds on earlier studies and combines results concerning the athletes personal reactions associated with sports injuries. It takes into account, among other things, private and external factors that are of importance during the rehabilitation process following sport injuries. This model will be used as the theoretical framework in this study. The first part of the model highlights the cognitive values associated with sports injuries, including self-efficacy. The second part of the model highlights the emotional response during sports injuries.

Therefore, the purpose of the present study was to investigate beach volleyball players' experiences of shoulder injury, rehabilitation and return to sport.

\section{MATERIALS AND METHODS}

\section{Participants}

Five players, four male and one female aged 27-42, who all played or had played beach volleyball at an elite level participated in the study. All had suffered a severe shoulder injury that had resulted in absence from training/games for at least 28 days, classified as a major injury, according to Ekstrand et al. (2011). The selection was made through a convenience principal, which meant that the author chose the participants (Deacon et al., 1999). All agreed to participate voluntarily after receiving information about the purpose of the study. They received oral and written information, and they could withdraw from the study at any time with-

Table 1. Background characteristics of research participants

\begin{tabular}{ll}
\hline & Participants $(\mathrm{n}=5)$ \\
\hline Injury & \\
Overload injury & 2 \\
Acute traumatic injury & 2 \\
Combination of overload and traumatic injury & 1 \\
Treatment & \\
Surgery & 2 \\
Physiotherapy & 2 \\
Conservative & 1 \\
\hline
\end{tabular}

out giving an explanation. Ethical approval was obtained from the Ethical Advisory Board in South East Sweden (Dnr. EPK 1962013).

The shoulder injuries, rehabilitation (Table 1) and return to sports took place between 2007-2012 for all participants.

\section{Procedure}

The interviews were conducted, by one of the authors, through Skype (video communication). Each interview lasted between 30$60 \mathrm{~min}$, and the participants had the opportunity to talk as long as they wanted without time restriction. The participants were also informed that they did not have to answer the questions if they preferred not to. A test interview was conducted to optimize the settings and to give the interviewer feedback. This test interview was not included in the study.

A qualitative approach was used (Trost, 2010). The interviews were semi-structured, which meant that the questions were pre determined; however, the order of the questions could vary from interview to interview and was determined by the development of the interview (Trost, 2010). The interviews were used for mapping the experience of, in connection with, the shoulder injury and what may affect the return to beach volleyball after such an injury. The results were then analysed in relation to the theoretical framework.

A content analysis was performed where the interviews were classified into smaller, meaning units. These were condensed and the centre of the meaning unit was highlighted. Thereby, these could be coded and categorized to fall into a theme (Table 2). The framework for the content analysis was provided from Graneheim and Lundman (2004).

\section{RESULTS}

When analysing the interviews, a content analysis resulted in seven themes emerging to describe the experience of a severe shoulder injury and what may affect the return to beach volleyball

Table 2. Overview of the content analysis

\begin{tabular}{|c|c|c|c|c|}
\hline Meaning units & Condensed units & Codes & Categories & Themes \\
\hline $\begin{array}{l}\text { As volley ball } \\
\text { player or beach } \\
\text { volley ball player } \\
\text { you always have } \\
\text { had more or less } \\
\text { pain in the } \\
\text { shoulder, so you } \\
\text { have.....that is a } \\
\text { problem }\end{array}$ & $\begin{array}{l}\text { More or less } \\
\text { pain in the } \\
\text { shoulder as a } \\
\text { beach volley- } \\
\text { ball } \\
\text { player }\end{array}$ & $\begin{array}{l}\text { Always pain } \\
\text { in } \\
\text { the shoulder }\end{array}$ & $\begin{array}{l}\text { Shoulder } \\
\text { injuries are } \\
\text { common }\end{array}$ & Injury \\
\hline
\end{tabular}


after such an injury. The six themes were: injury and pain, rehabilitation, prevention, goal setting, self-motivation and negative environmental factors. These themes are presented in the results in three categories: experiences associated with shoulder injury, what does the road back look like and how do you get back? Texts in italics are quotes from the interviews.

\section{Experiences associated with shoulder injury}

The participants' experiences of shoulder injury were divided into one theme: injury and pain.

\section{Injury and pain}

The two participants who underwent surgery to the shoulder had modified training during the six months of rehabilitation. One of them did not play for six months prior to surgery. All of the players returned to the same or higher level of playing after rehabilitation, although in some cases it took up to five years after the injury.

'The last six months prior to surgery, I could not really play ... eh ... maybe I played a little bit but not seriously or anything'.

All participants had previous experience of injury and rehabilitation. The general tone of the interviews was that the injury is something that is common in sports and was not anything unusual. There was also a tolerance to pain and it was not uncommon to play despite an injury, even though the player knew that it could aggravate the injury. The participants admitted that it was foolish to play with an injury but still did it so that their team member could play. Two participants stressed that in many situations there is no cooperation between the coach, the medical team and the player. This means that the player has to make the decisions on his or her own and also be the one who informs the coach of possible restrictions because of an injury when it comes to training and playing games. This could result in the player practicing and playing even though he/she is not ready, since it could be difficult to disappoint the coach and the other player.

'It is often a problem when the player meets with the medical team and then communicates it to the coach. The coach then says ok, but I had something different in mind. This makes it hard for the player, and helshe has to be strong and stick to the plan according to the injury. It's rare that the player is that strong, I think'.

All participants believe that shoulder pain is common in beach volleyball and that it is normal to play with some degree of pain.

\section{What does the way back to sports look like?}

The results can be divided into two themes: rehabilitation and prevention.

\section{Rehabilitation}

Since all participants had suffered previous injuries, they had prior experience of rehabilitation. One participant had even gone through rehabilitation of the shoulder. One of the participants expressed that injuries and rehabilitation is something of a 'deal-breaker' and expressed himself as follows:

'Either you break down and then you get notbing out of it or you go through it and become a better player'.

The common consensus was however that when you go through a rehabilitation period you get stronger mentally, when it comes to sports and you will be more prepared for any future injuries. Four of the participants felt it was important to get treatment from the same therapist throughout the rehabilitation and that he/she gladly returned to that therapist in case of a new injury. To have confidence in the therapist was necessary for the participants since being injured and going through rehabilitation is hard for your body and your mind. The participants agreed that if you did not trust your therapist you had to change. The participants stated that it was mentally hard to go through rehabilitation alone, compared to having support from a team. This meant that support from friends and family was viewed as very important, in combination with a positive physiotherapist. One of the participants felt it was best to be completely suspended from practice and being able to pay full attention to rehabilitation, while another expressed that as an elite athlete, it's always a race against time. One of the participants felt that setbacks in rehabilitation could be seen as burdensome and added that if you did not have setbacks it might be a sign that the rehabilitation was going too slowly. Another participant pointed out that it was time consuming to focus on rehabilitation. All of the participants thought that positive input and progress in rehabilitation were motivating factors. Two participants felt that their performance improved after rehab because of more technical work during that period of time. Incorrect technique was viewed as a risk factor when it came to injuries. The general view of the participants was that the coach was not particularly involved in the rehabilitation process. The participants stated that the coach advised them to:

'Do the exercise you feel comfortable doing'.

The rehabilitation was initially carried out with help from the physiotherapist. Two participants reported that they had had contact with the physiotherapist occasionally when needed, and one participant had to make his/her own decision as to when to go back to playing volleyball after rehabilitation. One participant thought it felt good to prolong recovery time and not rush back 
to full training in order to prevent setbacks or re-injury. All participants did complementary exercises during rehabilitation but no one stopped practicing. None of the participants stated that there had been a lack of motivation for rehabilitation or return to the sport; however, they found that it was difficult to determine when to totally rest from exercising or go on with the rehab. The training is often planned in great detail; therefore, it may sometimes be difficult to squeeze the rehab exercise into the programme. The consequence of this might be that there will be more hours of practice during rehabilitation than usual. Some of the participants expressed it as follows:

'You do what you usually do during practice, plus you add your rehab exercises so you end up doing more. This is, of course, risky business. I think this is the big difficulty during rehabilitation'.

\section{Prevention}

The participants felt that prevention of shoulder injuries was important and that was a view commonly held in beach volleyball. The same participants did his/her prevention exercises weekly to avoid re-injury.

'How are you supposed to train to not get injured again? I would really like to get some help and guidance'.

The majority of the participants felt that this was an area that could be developed more and that it was something that was lacking in beach volleyball; in addition, they perceived a need for more understanding from the traditional medicine.

\section{How do you get back?}

The participants' experiences and thoughts on their return to beach volleyball can be divided into three themes: negative environmental factors, goal setting and self-motivation.

\section{Negative environmental factors}

Some participants pointed out that there is a special bond between the players in beach volleyball, as there are only two players and no reserves in case of injury or illness. This was perceived as stressful and some reflections were:

'I did not feel pushed, but in a sport where we are only two my co-player is dependent on me'.

'If I get injured, I know my co-player will play with someone else'.

Other factors that some of the participants thought influenced how quickly they came back to playing matches was if it was an important game ahead. Some participants found it difficult to say no and refrain from training and playing match since they felt lack of support and pressured from their co-player and their coach.
The same participant was not satisfied with the coach's attitude. $\mathrm{He} / \mathrm{sh}$ felt that the coach wanted to influence the rehabilitation by having opinions on how the rehabilitation should be done.

'The chemistry between us was not good in that situation. The coach was thinking of my co-player's best and did not respect my injury which I think is rather short sighted.

\section{Goal setting}

All participants had a clear goal to get back to playing beach volleyball, and one participant expressed it as follows:

'There was no question about it... the way back. Yes, the chances to get back are good. There has never been any doubt'.

One of the participants who underwent an operation said that the goal of the operation was to be able to play beach volleyball again. All the participants felt that the process of returning to playing volleyball was the main objective. All agreed on the importance of having a clear goal with the rehabilitation. Dialogue with the physiotherapist seemed to help reach the goal.

\section{Self-motivation}

Four of the participants expressed that it was their own motivation that was the main reason for why they came back to playing after the shoulder injury. Stubbornness, own ambitions and self-imposed goals are other factors that the participants believe contributed to getting back to the game.

'They, buh... my own goals and my oun ambitions that pushed me'.

The participants believed that if you want to do something enough, if you think it is fun, then there are no limitations or obstacles when it comes to rehab after an injury. The participants also believed that time is important, that is, it takes time for rehabilitation and you must be able to give that time to the injury.

\section{DISCUSSION}

The purpose of the present study was to investigate beach volleyball players' experiences of shoulder injury, rehabilitation and return to the sport. The general tone of all participants was that shoulder injuries were common and typical of the sport. Goal setting and their own motivation seemed to be the main factors that influenced their return to sports after injury.

An Integrated Model of Response to sports injury (WieseBjörnsdal et al., 1998) serves as a theoretical framework for this study. As mentioned above, this model builds on combined results of earlier studies concerning reactions associated with sports injuries, taking into account cognitive values and the emotional re- 
sponses that have been observed in connection with sports injuries.

In this model, the authors describe the cognitive values based on a few different factors such as cause of injury, possibility of recovery and availability of social support. The athletes' cognitive values of these factors have been found to significantly correlate with their mood (Wiese-Björnsdal et al., 1998). The heart of the model is thus that the athletes' self-perception reflects their mood and behaviour with regard to the injury. If the athlete has a low self-esteem or sense of self, then the reaction will be different, compared to if the athlete has a high self-esteem. One of the participants in the study expressed that she felt that either you go through an injury and come out as a stronger athlete, or you stop and do not return after the injury. This is supported by other research that forms the basis of the model, where there is no demonstrated lower self-confidence of the athlete after injury (Brewer and Petrie, 1995; Smith et al.,1993), while other research found significantly lower self-esteem after injury (Chan and Grossman, 1988; McGowan et al., 1994). Self-efficacy, that is, individual's confidence in his/her ability to perform a certain action has been studied by various researchers (Wiese-Björnsdal et al., 1998). Since the term is task oriented, it means that it can only be applied to a specific task. Previous experience of rehabilitation provides higher self-efficacy in subsequent rehabilitation (Johnson, 1997). All participants had previous experience with injuries and rehabilitation, which according to the above reasoning would be an advantage. Some of the participants felt they were mentally stronger and also technically better after rehabilitation, which is also supported by previous research (Johnson, 1997; Nordahl et al., 2014). Other researchers have shown that there can be a factor that contributes to an individual's self-efficacy, namely, his/her Internal Locus of Control, thus the individual's belief that his/her actions can affect the outcome (Wallston and Wallston 1978; Thomée et al., 2007).

Social support was of importance to the participants, and some expressed that it was of great importance to have access to physiotherapy and access to the same physiotherapist as they had during earlier rehabilitation. Some participants pointed out that it was important to have support from family and friends. Likewise, the support of the teammate and coach played a big role when returning to the sport after injury. If support from the teammate and coach was lacking, the support from family, friends and physiotherapist became even more important. Nordahl et al. (2014) and Thomée et al. (2007) have come to similar conclusions that support from the social environment and enough time to go through rehabilitation are two important factors that play a role in the comeback after injury. Three of the participants stated that they did not believe that their teammate fully understood the extent of their injuries. This may be one reason as to why they had not experienced enough support from their teammate but instead perceived that their partner pressured them to play despite the injury.

Some common emotional responses connected to sports injuries, according to the model, are mood swings during rehabilitation or negative emotions that can be turned into positive emotions. The authors behind the model also highlight that some studies have seen extreme emotional reactions to injury. In some cases, it even led to severe depression and ultimately imminent risk of suicide (Smith and Millener, 1994). The authors point out that health professionals and coaches should be aware of such signals. Even though this may be a part of an athlete's life, not everyone gets these extreme emotional reactions. The vast majority of athletes cope with their injury.

Mood swings during rehabilitation were seen as more common in some participants than others. When the participants encountered setbacks in the rehabilitation the need for social support was more important, compared to when the rehabilitation was on schedule. Thus, a linear or static pattern of mood swings could not be seen, which is also supported in the model (Wiese-Björnsdal et al., 1998).

Wiese-Björnsdal et al. (1998) conclude that negative emotions can be turned into positive emotions, and that competitive athletes tend be more emotional during injury rehabilitation, as was seen in this study, compared to people who exercise for general fitness. Competitive athletes were also faster to return to sport after injury than recreational athletes. According to the model (Wiese-Björnsdal et al., 1998), one explanation for this could be that competitive athletes have more frustrations and mood changes because of the injury, which may contribute to higher levels of motivation to return to the sport. The authors behind the model also highlight that depending on the specific type of injury, one can assume that the emotional response varies. Often the severity of the injury is measured in time lost from the sport, but WieseBjörnsdal et al. (1998) argue that the character of the injury, if it is an overload injury, acute injury or surgery involved, probably plays a significant role when it comes to measuring the emotional response. In this study, all participants had been away from the sport for more than 28 days, but the character of the injury differs between participants. Wiese-Björnsdal et al. (1998) emphasize that in order to fully understand the cognitive values and the emotional responses that occur in connection with sports injuries, the social dynamic has to be taken into account as well as the cul- 
tural context that rules in the world of elite sports, where performing with pain could be seen as an everyday matter. Knowing that one's partner may play with someone else if you are injured is, of course, a factor that could push the player to train and play matches despite the injury.

In qualitative studies, there are some main points to take into account. The selection of participants should be large enough to give a fair idea, but not excessive, so that overview of the results can be maintained. In line with previous research (Nordahl et al., 2014), this study includes five participants, which is recommended as a minimum for qualitative interview studies.

In qualitative studies, the expression trustworthiness that includes credibility, dependability and transferability are used (Granheim and Lundman, 2004). Credibility deals with the focus of the research and refers to confidence in how well data and processes of analysis address the intended focus. In this study, the credibility was high since all participants were beach volleyball players or former players with extended knowledge about injury and rehabilitation, and they also came back after injury. Graneheim and Lundman (2004) also argue that the credibility depends on how well the interview analysis takes up bite-sized meaningful units, and whether the researcher categorized these properly or not. Quotes from interviews in the text can help to increase the credibility of the interview analysis as was done in this study, or to compare the results with previous studies as was done here with the study by Graneheim and Lundman (2004), which on the whole enhances the trustworthiness of this study.

Dependability refers to the degree to which the data change over time and also the researchers' decisions during the analysis process. The dependability in this study is probably high since the subject studied is an ongoing problem in sports. Trustworthiness also includes the question of transferability, meaning the possibility of transferring the findings to other settings or groups. It is probably possible to transfer the findings from this study to other groups of athletes (elite and non-elite) and not only limit it to beach volleyball.

All interviews were conducted and transcribed in a uniform manner by the same author, which contributes to increasing trustworthiness. Another strength of this study was the participants' enthusiasm to participate and their support in further developing prevention training and thus increasing knowledge of the factors that contribute to the return to sport after injury.

The findings of this study indicate that there are three distinct factors that increase the chances of getting back to beach volleyball after shoulder injury, including the player's self-motivation, together with a clear goal and support from the community, family, teammate and coach. Some of the participants thought they had become mentally stronger and also technically better after rehabilitation of their shoulder injury.

\section{CONFLICT OF INTEREST}

No potential conflict of interest relevant to this article was reported.

\section{REFERENCES}

Bahr R, Bahr IA. Incidence of acute volleyball injuries: a prospective cohort study of injury mechanisms and risk factors. Scand J Med Sci Sports 1997;7:166-171.

Bahr R, Reeser JC. Injuries among world-class professional beach volleyball players. The Fédération Internationale de Volleyball beach volleyball injury study. Am J Sports Med 2003;1:119-125.

Bandura A. Self-efficacy: toward a unifying theory of behavioral change. Psychol Rev 1977;84:191-215.

Bandura A. Health Promotion by Social Cognitive Means. Health Educ Behav 2004;31:143-164.

Brewer BW, Petrie T. A comparison between injured and uninjured football players on selected psychosocial variables. Academ Athlet J 1995;10:11-18.

Chan CS, Grossman HY. Psychological effects of running loss on consistent runners. Percept Motor Skills 1988;66:875-883.

Deacon D, Golding P, Murdock G, Pickering M. Researching Communications. London, UK, Arnolds, 1999.

Ekstrand J, Hägglund M, Waldén M. Injury incidence and injury patterns in professional football: the UEFA injury study. Br J Sports Med 2011;45:553-558.

Frey JH. Social risk and the meaning of sport. Sociol Sport J 1991;8:136145.

Graneheim UH, Lundman B. Qualitative content analysis in nursing research: concepts, procedures and measures to achieve trustworthiness. Nurse Educ Today 2004;24:105-112.

Johnson UA. Three-Year Follow-Up of Long-Term injured Competitive Athletes: influence of Psychological Risk Factors on Rehabilitation. J Sports Rehabil 1997;6:256-271.

McGowan RW, Pierce EF, Williams M, Ea 'stman NM. Athletic injury and self-diminution. J Sports Med Phys Fitness 1994;34:299-304.

Nordahl B, Sjöström R, Westin M, Werner S, Alricsson M. Experiences of returning to elite alpine skiing after ACL injury and ACL reconstruction. Int J Adolesc Med Health 2014;26:69-77. 
Podlog L, Eklund RC. Return to sport after serious injury: a retrospective examination of motivation and psychological outcomes. J Sport Rehabil 2005;14:20-34.

Reeser JC, Verhagen E, Briner WW, Askeland TI, Bahr R. Strategies for the prevention of volleyball related injuries. Br J Sports Med 2006;40:594600.

Smith AM, Millener AK. Injured athletes and the risk of suicide. J Athlet Training 1994;29:337-341.

Smith AM, Stuart ML, Weise-Björnstal DM, Milliner EK, O'Fallon WJ, Crowson CS. Competitive athletes: pre and post injury mood state and self-esteem. Mayo Clin Proc 1993;68:939-947.
Thomeé P, Währborg P, Börjesson M, Thomeé R, Eriksson B, Karlsson J. Determinants of self-efficacy in the rehabilitation of patients with anterior cruciate ligament injury. J Rehabil Med 2007;39:486-492.

Trost, J. Qualitative interviews 4th edition. [Kvalitativa intervjuer 4:e upplagan]: Lund, Sweden, Studentlitteratur, 2010.

Wiese-Björnsdal DM, Smith AM, Shaffer SM, Morrey MA. An integrated model of response to sports injury: Psychological and sociological dynamics. J Appl Sport Psychol 1998;10:46-69.

Wallston BS, Wallston KA. Locus of control and health: A review of the literature. Health Educ Monographs 1978;6:107-117. 